Article

\title{
Association between Intraoperative Blood Pressure Drop and Clinically Significant Hypoperfusion in Abdominal Surgery: A Cohort Study
}

\author{
Zbigniew Putowski ${ }^{1, *}$, Szymon Czajka ${ }^{2}$ and Lukasz J. Krzych ${ }^{2}$ (D) \\ 1 Students' Scientific Society, Department of Anesthesiology and Intensive Care, School of Medicine in \\ Katowice, Medical University of Silesia, 14 Medyków Street, 40-752 Katowice, Poland \\ 2 Department of Anesthesiology and Intensive Care, School of Medicine in Katowice, Medical University of \\ Silesia, 14 Medyków Street, 40-752 Katowice, Poland; szymon_czajka@wp.pl (S.C.); \\ lkrzych@sum.edu.pl (Ł.J.K.) \\ * Correspondence: putowski.zbigniew@gmail.com
}

Citation: Putowski, Z.; Czajka, S.; Krzych, Ł.J. Association between Intraoperative Blood Pressure Drop and Clinically Significant Hypoperfusion in Abdominal Surgery: A Cohort Study. J. Clin. Med. 2021, 10, 5010. https://doi.org/ $10.3390 / \mathrm{jcm} 10215010$

Academic Editor: Michael Froelich

Received: 20 September 2021

Accepted: 21 October 2021

Published: 28 October 2021

Publisher's Note: MDPI stays neutral with regard to jurisdictional claims in published maps and institutional affiliations.

Copyright: (c) 2021 by the authors. Licensee MDPI, Basel, Switzerland. This article is an open access article distributed under the terms and conditions of the Creative Commons Attribution (CC BY) license (https:// creativecommons.org/licenses/by/ $4.0 /)$.

\begin{abstract}
The recent consensus by the Perioperative Quality Initiative (POQI) on intraoperative hypotension ( $\mathrm{IOH}$ ) stated that mean arterial pressure (MAP) below $60-70 \mathrm{mmHg}$ is associated with myocardial infarction (MI), acute kidney injury (AKI), death and also that $\mathrm{IOH}$ is a function of not only severity but also of duration. However, most of the data come from large, heterogeneous cohorts of patients who underwent different surgical procedures and types of anaesthesia. We sought to assess how various definitions of $\mathrm{IOH}$ can predict clinically significant hypoperfusive outcomes in a homogenous cohort of generally anesthetised patients undergoing abdominal surgery, taking into account thresholds of MAP and their time durations. The data for this study come from a prospective cohort study in which patients who underwent abdominal surgery between 1 October 2018 and 15 July 2019 in the university hospital in Katowice were included in the analysis. We analysed perioperative data to assess how various $\mathrm{IOH}$ thresholds can predict hypoperfusive outcomes (defined as myocardial injury, acute kidney injury or stroke). 508 patients were included in the study. The total number of cases of clinically significant hypoperfusion was $38(7.5 \%)$. We found that extending durations of low MAP, i.e., below $55 \mathrm{mmHg}, 60 \mathrm{mmHg}, 65 \mathrm{mmHg}$ and $70 \mathrm{mmHg}$, were associated with the development of either AKI, MI or stroke. It was observed that for narrower and lower hypotension thresholds, the time required to induce complications is shorter. Patients who suffered from AKI/MI/Stroke experienced more episodes of any of the IOH definitions applied. Absolute $\mathrm{IOH}$ thresholds were superior to the relative definitions. For patients undergoing abdominal surgery, it is vital to prevent the extended durations of intraoperative mean arterial pressure below $70 \mathrm{mmHg}$. Finally, there appears to be no need to guide intraoperative haemodynamic therapy based on pre-induction values and, consequently, on relative drops of MAP.
\end{abstract}

Keywords: hypotension; intraoperative period; ischemia; postoperative complications; general surgery

\section{Background}

Over the years, there has been an increasing level of evidence linking intraoperative hypotension $(\mathrm{IOH})$ to mortality, even one-year post-surgery [1]. IOH can be induced by a variety of patient- and procedure-related factors, including hypovolaemia, vasodilation and myocardial depression [2]. Additionally, ischemia-reperfusion injury due to $\mathrm{IOH}$ may contribute to organ damage [3]. IOH causes hypoperfusion of the vital organs such as the brain, the heart and the kidneys, leading to their dysfunction. A stroke, acute kidney injury (AKI) and myocardial infarction (MI) are the most distinct results of the clinically significant IOH. The lack of standard definitions for hypotension results in reported incidences from $5 \%$ to even $99 \%$, depending on which definition is used and which blood pressure components are considered [4]. The recent consensus by the Perioperative Quality Initiative (POQI) on 
IOH stated that mean arterial pressure (MAP) below $60-70 \mathrm{mmHg}$ is associated with MI, $\mathrm{AKI}$, death and also that $\mathrm{IOH}$ is a function of not only severity but also of duration. However, these conclusions come from large cohorts of heterogenous patient populations who underwent different surgical procedures and types of anaesthesia [5-10]. Additionally, in many of these studies, IOH thresholds were pre-set by investigators. Therefore, we sought to assess how various definitions of $\mathrm{IOH}$ can predict clinically significant hypoperfusive outcomes in a fairly homogenous cohort of generally anesthetized patients undergoing abdominal surgery, taking into account thresholds of MAP and their time durations.

\section{Methods}

In this cohort study, we included 590 consecutive patients who underwent abdominal surgery between 1 October 2018 and 15 July 2019 in the University Clinical Center prof. K. Gibiński Silesian Medical University in Katowice. Procedures of organ procurement ( $n=11)$, reoperations $(n=24)$, procedures performed under local anaesthesia or monitored anaesthetic supervision $(n=33)$, and those classified as immediate according to the NCEPOD Classification of Intervention [11] $(n=14)$ were excluded. The flow diagram for the patient selection process is presented in Figure 1. Demographic and medical data were recorded, including sex, age, weight, height, comorbidities and their pharmacological treatment, according to the ICD 10 criteria [12]. Body mass index (BMI) and Charlson Comorbidity Index (CCI) were subsequently calculated. Type and duration of anaesthesia, and type, duration and urgency of surgery were recorded [13]. The perioperative risk was assessed based on individual patients' risk, according to the American Society of Anesthesiology (ASA) physical status (PS) classification [14], and procedural risk, according to the European Society of Cardiology and European Society of Anaesthesiology recommendations [15]. Primary arterial hypertension was diagnosed based on medical records. Currently used antihypertensive therapy was evaluated based on medical charts.

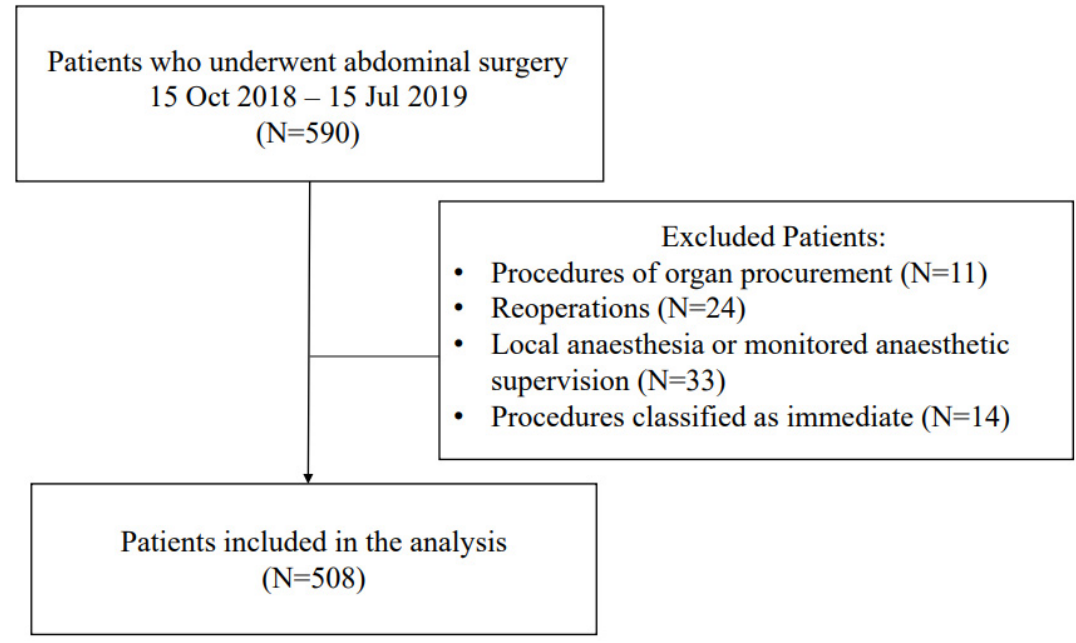

Figure 1. Flow diagram for the patient selection process.

The majority of patients had their systolic (SBP) and diastolic blood pressure (DBP) measured on a non-dominant arm with an automated oscillometric non-invasive BP monitoring device (Dräger Infinity Gamma XL) with a cuff of appropriate size depending on the patient's arm circumference and recorded in five min intervals during anaesthesia from the first pre-induction measurement until the last measurement during recovery from anaesthesia in the operating theatre. MAP values were automatically calculated. For patients with invasive blood pressure monitoring, BP was measured directly. A need for norepinephrine (NE) use, its doses and duration of infusion, together with intraoperative fluid balance, were recorded and analysed.

The following absolute MAP thresholds were distinguished: $<55 \mathrm{mmHg},<60 \mathrm{mmHg}$, $<65 \mathrm{mmHg},<70 \mathrm{mmHg},<75 \mathrm{mmHg}$. Time spent under each of described thresholds was 
calculated. Additionally, relative thresholds were explored, defined as a MAP drop from baseline value (pre-induction MAP), namely: $>20 \%,>25 \%,>30 \%,>35 \%,>40 \%$. Again, the duration of such $\mathrm{IOH}$ was also measured. The number of episodes of $\mathrm{IOH}$ recorded during the procedure (i.e., one 5-min interval accounted for one episode) were assessed.

The number of episodes spent under different $\mathrm{IOH}$ thresholds was calculated, and their association with a hypoperfusive outcome (AKI, MI or stroke) was assessed. The outcomes were defined according to their international definitions [16-18]. By using the ROC curve analysis of time spent under each of the $\mathrm{IOH}$ thresholds, we established dichotomous $\mathrm{IOH}$ thresholds (e.g., $>5$ episodes of $\mathrm{MAP}<60 \mathrm{mmHg}$ ). Those definitions were then included in the multivariable logistic regression models.

STROBE (strengthening the reporting of observational studies in epidemiology) statement was applied for appropriate reporting (Supplementary Materials: Table S1) [19].

Statistical analysis was performed using MedCalc Statistical Software version 18.1 (MedCalc Software Ltd., Ostend, Belgium). Continuous variables were expressed using medians and interquartile ranges (IQR). Qualitative variables were expressed as absolute values and percentages. Between-group differences for quantitative variables were assessed using the Mann-Whitney U test or Kruskal-Wallis test. Their distribution was verified with Shapiro-Wilk test. Chi-square or Fisher's exact test was applied for qualitative variables. Areas Under the Receiver Operating Characteristics (AUROC) curves with 95\% CIs were calculated to assess the diagnostic accuracy of consecutive models. All tests were two-tailed. A " $p$ " value $<0.05$ was considered statistically significant. All variables with significance below 0.05 in univariable testing were selected for the stepwise multivariable logistic regressions.

\section{Results}

The study group comprised 508 patients: 239 (46.6\%) males and 269 (53.4\%) females. The median age of patients was 62 years (IQR 46-68). Detailed study group characteristics are presented in Table 1. The median duration of anaesthesia was $230 \mathrm{~min}$ (IQR 130-340). There were 49 (9.6\%) non-elective procedures and $245(48.2 \%)$ oncologic surgeries. All patients received fentanyl, $94.5 \%$ of patients received propofol and $87 \%$ received sevoflurane. Anaesthesia- and surgical procedure-related variables are depicted in Table 2 and in the Supplementary Materials: Table S2.

Table 1. Preoperative population characteristics.

\begin{tabular}{cccc}
\hline Variable & Outcome $(-) n=470$ & Outcome (+) $n=38$ & $p$-Value \\
\hline Age (years) & $61(45-68)$ & $67(62-75)$ & 0.0002 \\
Males & $219(46.6)$ & $20(52.6)$ & 0.4 \\
BMI (kg m $\left.{ }^{-2}\right)$ & $25.6(22.5-29.0)$ & $27.1(21.9-29.8)$ & 0.4 \\
Chronic arterial hypertension & $205(43.6)$ & $29(76.3)$ & $<0.0001$ \\
Chronic Kidney Disease & $8(1.7)$ & $5(38.5)$ & $<0.0001$ \\
Diabetes mellitus & $57(12.1)$ & $4(10.5)$ & 0.8 \\
Pre-induction SBP (mmHg) & $140(125-153)$ & $142.5(130-155)$ & 0.2 \\
Pre-induction MAP (mmHg) & $101.7(92.0-110.0)$ & $101.5(95.0-110.0)$ & 0.6 \\
ACEI/ARB & $97(20.6)$ & $13(34.2)$ & 0.05 \\
B-blocker & $118(25.1)$ & $15(39.5)$ & 0.05 \\
Calcium antagonist & $39(8.3)$ & $4(10.5)$ & 0.6 \\
ASA PS class III/IV/V & $189(40.2)$ & $26(68.4)$ & 0.0007 \\
CCI (pts) & $3(1-5)$ & $5(3-7)$ & $<0.0001$ \\
Premedication & $284(60.4)$ & $21(55.3)$ & 0.5 \\
\hline
\end{tabular}

Continuous variables are expressed as median and interquartile range (in brackets). Qualitative variables are expressed as absolute values and/or percent (in brackets). 
Table 2. Intraoperative population characteristics.

\begin{tabular}{|c|c|c|c|}
\hline Variable & Outcome $(-) n=470$ & Outcome $(+) n=38$ & $p$-Value \\
\hline $\begin{array}{c}\text { Adjunction of regional } \\
\text { anaesthesia (number of cases) }\end{array}$ & $31(6.6)$ & $9(23.7)$ & 0.0002 \\
\hline $\begin{array}{c}\text { Invasive blood pressure } \\
\text { monitoring (number of cases) }\end{array}$ & $67(14.7)$ & $14(36.8)$ & 0.0004 \\
\hline Procedure Risk I* & $44(9.4)$ & $1(2.6)$ & 0.1 \\
\hline Procedure Risk II * & $314(66.8)$ & $21(55.3)$ & 0.1 \\
\hline Procedure Risk III * & $112(23.8)$ & $16(42.1)$ & 0.01 \\
\hline $\begin{array}{l}\text { Oncological procedure } \\
\text { (number of cases) }\end{array}$ & $219(46.6)$ & $26(68.4)$ & 0.009 \\
\hline $\begin{array}{l}\text { Catecholamine use } \\
\text { (number of cases) }\end{array}$ & $197(41.9)$ & $30(78.9)$ & $<0.0001$ \\
\hline $\begin{array}{l}\text { Time of catecholamine } \\
\text { administration from the } \\
\text { induction of anaesthesia ( } \mathrm{min} \text { ) }\end{array}$ & $40.0(20.0-80.0)$ & $37.5(15.0-60.0)$ & 0.4 \\
\hline $\begin{array}{l}\text { Catecholamine dose } \\
\left(\mu \mathrm{kg}^{-1} \mathrm{~min}^{-1}\right)\end{array}$ & $0.054(0.042-0.090)$ & $0.070(0.048-0.091)$ & 0.3 \\
\hline Procedure duration (min) & $215.0(120.0-330.0)$ & $372.5(235.0-492.0)$ & $<0.0001$ \\
\hline Fluid dose $\left(\mathrm{mL} \mathrm{kg}^{-1} \mathrm{~h}^{-1}\right)$ & $6.78(5.16-8.76)$ & $6.674 .74-8.58)$ & 0.5 \\
\hline
\end{tabular}

Depending on the threshold applied, IOH could be diagnosed in $10.7-92 \%$ of all patients. The number of $\mathrm{IOH}$ cases increased gradually with the restriction of the $\mathrm{IOH}$ threshold (Table 3).

Table 3. Absolute and relative MAP thresholds and their association with the negative outcome.

\begin{tabular}{cccc}
\hline Threshold & Outcome $(-\mathbf{)} n=\mathbf{4 7 0}$ & Outcome $(+) \boldsymbol{n}=\mathbf{3 8}$ & $\boldsymbol{p}$-Value \\
\hline$<55 \mathrm{mmHg}$ & $44(9.4)$ & $10(26.3)$ & 0.001 \\
$<60 \mathrm{mmHg}$ & $107(22.9)$ & $17(44.7)$ & 0.002 \\
$<65 \mathrm{mmHg}$ & $218(46.4)$ & $26(68.4)$ & 0.009 \\
$<70 \mathrm{mmHg}$ & $345(73.4)$ & $29(76.3)$ & 0.6 \\
$<75 \mathrm{mmHg}$ & $412(88.0)$ & $35(92.1)$ & 0.4 \\
Drop $>$ 20\% from baseline & $432(91.9)$ & $35(92.1)$ & 0.9 \\
Drop $>$ 25\% from baseline & $391(83.2)$ & $33(86.8)$ & 0.5 \\
Drop $>30 \%$ from baseline & $319(67.9)$ & $31(81.6)$ & 0.07 \\
Drop $>35 \%$ from baseline & $243(51.7)$ & $25(65.8)$ & 0.09 \\
Drop $>40 \%$ from baseline & $162(34.5)$ & $23(60.5)$ & 0.001 \\
\hline
\end{tabular}

Qualitative variables are expressed as absolute values and/or percent (in brackets).

The composite primary outcome was diagnosed in 38 (7.5\%) patients, including 32 cases of AKI $(6.3 \%), 3$ cases of MI $(0.6 \%)$ and one event of stroke $(0.2 \%)$. The association between the occurrence of a certain IOH threshold and the outcome is presented in Table 3 .

In regards to the number of episodes of certain $\mathrm{IOH}$ thresholds, a significant difference between patients who suffered from the hypoperfusion outcomes and patients who did not experience it was observed. With each increase in the $\mathrm{IOH}$ threshold, the number of episodes of such hypotension increased and was greater for patients who experienced hypoperfusive outcomes (Table 4). By using the ROC curve analysis of time spent under each of the predetermined thresholds, we established dichotomous $\mathrm{IOH}$ thresholds (Table 4). Those definitions were then included in the multivariable logistic regression models (Table 5). Only thresholds based on absolute MAP values were statistically significant in the multivariable models. 
Table 4. Number of episodes spent under each of absolute and relative IOH thresholds.

\begin{tabular}{|c|c|c|c|c|}
\hline Threshold & $\begin{array}{l}\text { Outcome }(-) \\
n=470\end{array}$ & $\begin{array}{l}\text { Outcome }(+) \\
\quad n=38\end{array}$ & $\begin{array}{l}\text { Best Cut-Off } \\
\text { Threshold in } \\
\text { Predicting Outcome } \\
(+)\end{array}$ & $p$-Value \\
\hline$<55 \mathrm{mmHg}$ & $0(0-0)$ & $0(0-1)$ & $>0$ & 0.001 \\
\hline$<60 \mathrm{mmHg}$ & $0(0-0)$ & $0(0-2)$ & $>0$ & 0.0009 \\
\hline$<65 \mathrm{mmHg}$ & $0(0-2)$ & $2(0-3)$ & $>1$ & 0.003 \\
\hline$<70 \mathrm{mmHg}$ & $2(0-6)$ & $6(1-16)$ & $>4$ & 0.01 \\
\hline$<75 \mathrm{mmHg}$ & $7(2-13)$ & $13(3-29)$ & $>17$ & 0.005 \\
\hline Drop $>20 \%$ from baseline & $15(5-32)$ & $29(9-55)$ & $>27$ & 0.006 \\
\hline Drop $>25 \%$ from baseline & $9(1-19)$ & $16(3-36)$ & $>20$ & 0.04 \\
\hline Drop $>30 \%$ from baseline & $3(0-10)$ & $5(1-19)$ & $>2$ & 0.03 \\
\hline Drop $>35 \%$ from baseline & $1(0-3)$ & $2(0-6)$ & $>4$ & 0.04 \\
\hline Drop $>40 \%$ from baseline & $0(0-1)$ & $1(0-3)$ & $>0$ & 0.001 \\
\hline
\end{tabular}

Continuous variables are expressed as median and interquartile range (in brackets). Cut-off points for number of $\mathrm{IOH}$ episodes were calculated by using ROC-curve analysis.

Table 5. Multivariable logistic regression models for prediction of the hypoperfusion-related events. Adjusted for chronic kidney disease, procedure duration and arterial hypertension (Supplementary Materials: Table S3).

\begin{tabular}{ccc}
\hline Model & OR (95\% CI) & $p$-Value \\
\hline$>0$ episodes of MAP $<55 \mathrm{mmHg}$ & $2.56(1.05-6.26)$ & 0.039 \\
$>0$ episodes of MAP $<60 \mathrm{mmHg}$ & $2.61(1.22-5.59)$ & 0.01 \\
$>1$ episodes of MAP $<65 \mathrm{mmHg}$ & $2.50(1.17-5.30)$ & 0.017 \\
$>4$ episodes of MAP $<70 \mathrm{mmHg}$ & $2.67(1.26-5.67)$ & 0.01 \\
$>17$ episodes of MAP $<75 \mathrm{mmHg}$ & $*$ & $*$ \\
$>27$ episodes of MAP drop $>20 \%$ from baseline & $*$ & $*$ \\
$>20$ episodes of MAP drop $>25 \%$ from baseline & $*$ & $*$ \\
$>2$ episodes of MAP drop $>30 \%$ from baseline & $*$ & $*$ \\
$>4$ episodes of MAP drop $>35 \%$ from baseline & $*$ & $*$ \\
$>0$ episodes of MAP drop $>40 \%$ from baseline & $*$ & $*$ \\
\hline
\end{tabular}

Other variables included in the models were as follows: Chronic Kindey Disease (1/0), duration of the procedure (per $1 \mathrm{~min}$ ), arterial hypertension $(1 / 0) .{ }^{* * \prime \prime} \mathrm{IOH}$ thresholds that failed to be included in the multivariable models.

\section{Discussion}

In this fairly homogenous abdominal surgery cohort, we found that extending durations of low MAP, i.e., below $55 \mathrm{mmHg}, 60 \mathrm{mmHg}$, $65 \mathrm{mmHg}$ and $70 \mathrm{mmHg}$, were associated with the development of either AKI, MI or stroke. There was a relationship between stricter $\mathrm{IOH}$ thresholds and their shorter duration required to be associated with the postoperative complications. Patients who suffered from AKI/MI/stroke experienced more episodes of any of the IOH definitions applied. Absolute IOH thresholds were superior to the relative definitions.

The results of our study are consistent with previous reports $[4,10]$. In a study by Walsh and Sun, any duration of MAP $<55 \mathrm{mmHg}$ was associated with the development of AKI and cardiac complications [6,8]. In Walsh's study, OR appeared much lower when assessing the risk of AKI (1.18 for 1-5 min and 1.19 for 6-10 min) and MI (1.30 for 1-5 min and 1.47 for $6-10 \mathrm{~min}$ ). We believe such discrepancy could be a result of the difference in the study population. In our patient population, the median age was 62 years, whereas in Walsh's cohort, it was approximately 55 years. In regards to the Charlson comorbidity index, our patients were also sicker (median 3 vs. 1 point). Considering the fraction of 3 rd-grade procedural risk $(25.2 \%)$ and that almost half of the procedures performed were oncological, we believe that the $\mathrm{IOH}$ effect on hypoperfusion in our cohort can have a substantially higher effect; therefore, higher OR occurred [15,20]. Indeed, Jang's study, albeit performed on an orthopaedic population with a mean age of 77 years, showed that MAP $<55-60 \mathrm{mmHg}$ recorded for more than $5 \mathrm{~min}$ (which probably corresponds to at least 
two episodes of MAP < 55 in our cohort) is associated with postoperative acute kidney injury with a risk of 5.14 (CI 95\% 1.54-20.35, $p=0.012$ ) [21].

By introducing relative $\mathrm{IOH}$ thresholds, we sought to explore whether relative thresholds are better suited for predicting hypoperfusive events. We found that these thresholds are not good enough to predict postoperative complications as they were not significant in multivariable models. According to the POQI statement, absolute thresholds appear to be as predictive of renal and cardiac injury as relative thresholds [4]. In our analysis, after adjustment for a number of confounding factors, only absolute thresholds were significant in relation to postoperative AKI/MI/Stroke. Based on our results, we believe that there is no need to guide intraoperative haemodynamic treatment on relative MAP drops.

As mentioned above, there was a relationship between stricter $\mathrm{IOH}$ thresholds and their shorter duration required to be associated with postoperative complications. Interestingly, significant IOH thresholds (Table 5) presented similar ORs and 95\% CIs. We, therefore, speculate that experiencing at least one episode of $\mathrm{MAP}<55 \mathrm{mmHg}$ is somewhat equal to experiencing at least four episodes of $\mathrm{MAP}<70 \mathrm{mmHg}$, et cetera. Those findings are in tune with several research papers and were additionally confirmed by the POQI statement that, essentially, intraoperative hypotension is a mixture of its severity and duration and is associated with AKI, MI and death [5,10]. In summary, conclusions from large, heterogeneous cohorts may be extrapolated on this homogeneous abdominal surgery population [5-10].

\section{Limitations}

The above-mentioned findings should be interpreted with caution due to a number of possible confounding factors. Firstly, a pre-induction MAP value was defined as "baseline" MAP. It is possible that such measurement does not represent a true "baseline" as it could be influenced by stress or premedication. However, it was demonstrated that BP measurements obtained on the day of the surgery were similar to those obtained via primary care [22]. Secondly, due to the fact that BP was measured in 5-min intervals, we chose not to quantify the duration of IOH in minutes but in episodes. This, to a certain extent, limits us from assessing a relationship between $\mathrm{IOH}$ severity and its duration. Thirdly, the true association between $\mathrm{IOH}$ and hypoperfusive outcomes may be masked by the use of catecholamines. Patients who suffered from postoperative complications more often received catecholamines during the procedure. A potential generalisability of our study indeed suffers from limited study population and its homogeneity (general anaesthesia, abdominal surgery), which is, on the other hand, one of the true strengths of our research $[6,19,23]$. Fourthly, patients with postoperative hypoperfusion were generally sicker (had higher CCI), which is another source of bias.

The major portion of the composite outcome consisted of AKI (32 cases). This explains why chronic kidney disease was such a strong predictor of the composite outcome (Table 5 and Supplementary Materials). Therefore, the multivariable models are greatly determined by AKI and not the other dependent variables (MI or Stroke). Therefore, we cannot imply the association between $\mathrm{IOH}$ and the occurrence of $\mathrm{MI}$ and stroke, and rather, just AKI. MI and stroke were rare, and the study was underpowered to find associations for these outcomes.

In our study, blood pressures after discharging the patient from the operating theatre were not studied. However, the role of the postoperative care period in the adverse outcomes observed cannot be underestimated. Another potential limitation is that the size of our cohort may be underpowered to detect certain associations. It is possible that, e.g., higher $\mathrm{IOH}$ thresholds are still associated with postoperative complications, albeit not shown directly by our study. Finally, this is an observational study, and no causal association between $\mathrm{IOH}$ and hypoperfusive outcomes can be demonstrated. 


\section{Conclusions}

For patients undergoing abdominal surgery, it is vital to prevent the extended durations of intraoperative mean arterial pressure below $70 \mathrm{mmHg}$. There is a strong interplay between the severity and duration of intraoperative hypotension. Finally, there appears to be no need to guide intraoperative haemodynamic therapy based on pre-induction values and, consequently, on relative drops of MAP.

Supplementary Materials: The following are available online at https:/ /www.mdpi.com/article/10 .3390/jcm10215010/s1, Table S1: STROBE statement checklist. Table S2: Types of surgery. Table S3: Multivariate logistic regression models in predicting the occurrence of hypoperfusive outcomes.

Author Contributions: Z.P., S.C. and Ł.J.K. gave substantial contributions to the conception and the design of the manuscript; Z.P. and S.C. acquired, analysed and interpreted the data. All authors participated in drafting the manuscript; authors E.J.K. and Z.P. revised it critically. All authors have read and agreed to the published version of the manuscript.

Funding: This research received no external funding.

Institutional Review Board Statement: Ethical review and approval were waived for this study, due to the retrospective and non-interventional design of the study and that the study complies with Section 21 and 22 of the Act of 5 December 1996 on the Medical Profession (Poland). A link to the legislation: https: / isap.sejm.gov.pl/isap.nsf/download.xsp/WDU19970280152/O/D19970152.pdf (accessed on 15 April 2021).

Informed Consent Statement: Informed consent was obtained from all subjects involved in the study.

Data Availability Statement: The datasets used and/or analysed during the current study are available from the corresponding author on reasonable request.

Conflicts of Interest: The authors declare that they have no conflict of interest.

\section{References}

1. $\quad$ Bijker, J.B.; van Klei, W.A.; Vergouwe, Y.; Eleveld, D.J.; van Wolfswinkel, L.; Moons, K.G.; Kalkman, C.J. Intraoperative hypotension and 1-year mortality after noncardiac surgery. Anesthesiology 2009, 111, 1217-1226. [CrossRef] [PubMed]

2. Ke, J.X.C.; George, R.B.; Beattie, W.S. Making sense of the impact of intraoperative hypotension: From populations to the individual patient. Br. J. Anaesth. 2018, 121, 689-691. [CrossRef] [PubMed]

3. Devereaux, P.J.; Yang, H.; Yusuf, S.; Guyatt, G.; Leslie, K.; Villar, J.C.; Xavier, D.; Chrolavicius, S.; Greenspan, L.; Pogue, J.; et al. Effects of extended-release metoprolol succinate in patients undergoing non-cardiac surgery (POISE trial): A randomised controlled trial. Lancet 2008, 371, 1839-1847. [PubMed]

4. Sessler, D.I.; Bloomstone, J.A.; Aronson, S.; Berry, C.; Gan, T.J.; Kellum, J.A.; Plumb, J.; Mythen, M.G.; Grocott, M.P.; Edwards, M.R.; et al. Perioperative Quality Initiative consensus statement on intraoperative blood pressure, risk and outcomes for elective surgery. Br. J. Anaesth. 2019, 122, 563-574. [CrossRef] [PubMed]

5. Mascha, E.J.; Yang, D.; Weiss, S.; Sessler, D.I. Intraoperative Mean Arterial Pressure Variability and 30-day Mortality in Patients Having Noncardiac Surgery. Anesthesiology 2015, 123, 79-91. [CrossRef] [PubMed]

6. Walsh, M.; Devereaux, P.J.; Garg, A.X.; Kurz, A.; Turan, A.; Rodseth, R.N.; Cywinski, J.; Thabane, L.; Sessler, D.I. Relationship between intraoperative mean arterial pressure and clinical outcomes after noncardiac surgery: Toward an empirical definition of hypotension. Anesthesiology 2013, 119, 507-515. [CrossRef] [PubMed]

7. Monk, T.G.; Bronsert, M.R.; Henderson, W.G.; Mangione, M.P.; Sum-Ping, S.T.J.; Bentt, D.R.; Nguyen, J.D.; Richman, J.S.; Meguid, R.A.; Hammermeister, K.E. Association between intraoperative hypotension and hypertension and 30-day postoperative mortality in noncardiac surgery. Anesthesiology 2015, 123, 307-319. [CrossRef] [PubMed]

8. Sun, L.Y.; Wijeysundera, D.N.; Tait, G.A.; Beattie, W.S. Association of intraoperative hypotension with acute kidney injury after elective noncardiac surgery. Anesthesiology 2015, 123, 515-523. [CrossRef] [PubMed]

9. Van Waes, J.A.R.; Van Klei, W.A.; Wijeysundera, D.N.; Van Wolfswinkel, L.; Lindsay, T.F.; Beattie, W.S. Association between intraoperative hypotension and myocardial injury after vascular surgery. Anesthesiology 2016, 124, 35-44. [CrossRef] [PubMed]

10. Salmasi, V.; Maheshwari, K.; Yang, D.; Mascha, E.J.; Singh, A.; Sessler, D.I.; Kurz, A. Relationship between Intraoperative Hypotension, Defined by Either Reduction from Baseline or Absolute Thresholds, and Acute Kidney and Myocardial Injury after Noncardiac Surgery: A Retrospective Cohort Analysis. Anesthesiology 2017, 126, 47-65. [CrossRef] [PubMed]

11. National Confidential Enquiry into Patient Outcome and Death. n.d. Available online: www.ncepod.org.uk/classification.html (accessed on 17 October 2020).

12. World Health Organization. ICD-10: International Statistical Classification of Diseases and Related Health Problems: Tenth Revision; WHO: Geneva, Switzerland, 2004. 
13. World Health Organization. International Classification of Diseases: [9th] Ninth Revision, Basic Tabulation List with Alphabetic Index; WHO: Geneva, Switzerland, 1978; 331p.

14. Doyle, D.J.; Goyal, A.; Bansal, P.; Garmon, E.H. American Society of Anesthesiologists Classification (ASA Class). 2020. Available online: https:/ / www.ncbi.nlm.nih.gov/books/NBK441940/ (accessed on 17 October 2020).

15. Kristensen, S.D.; Knuuti, J.; Saraste, A.; Anker, S.; Bøtker, H.E.; De Hert, S.; Ford, I.; Gonzalez-Juanate, J.R.; Gorene, B.; Heyndrickx G.R.; et al. 2014 ESC/ESA Guidelines on non-cardiac surgery: Cardiovascular assessment and management: The Joint Task Force on non-cardiac surgery: Cardiovascular assessment and management of the European Society of Cardiology (ESC) and the European Society of Anaesth. Eur. Heart J. 2014, 35, 2383-2431. [PubMed]

16. Kellum, J.A.; Lameire, N.; Aspelin, P.; Barsoum, R.S.; Burdmann, E.A.; Goldstein, S.L.; Herzog, C.A.; Joannidis, M.; Kribben, A.; Levey, A.S.; et al. Kidney disease: Improving global outcomes (KDIGO) acute kidney injury work group. KDIGO clinical practice guideline for acute kidney injury. Kidney Int. 2012, 2, 1-138.

17. Thygesen, K.; Alpert, J.S.; Jaffe, A.S.; ESC Scientific Document Group; Chaitman, B.R.; Bax, J.J.; Morrow, D.A.; White, H.D. Fourth universal definition of myocardial infarction (2018). Eur. Heart J. 2019, 40, 237-269. [CrossRef]

18. Ringleb, P.; Bousser, M.; Ford, G.; Bath, P.; Brainin, M.; Caso, V.; Cervera, Á.; Chamorro, A.; Cordonnie, C.; Csiba, L.; et al. Guidelines for management of ischaemic stroke and transient ischaemic attack 2008 the European Stroke Organization (ESO) Committee and the ESO Writing Committee Executive. Stroke 2008, 25, 6855-6859.

19. Wesselink, E.M.; Kappen, T.H.; Torn, H.M.; Slooter, A.J.C.; van Klei, W.A. Intraoperative hypotension and the risk of postoperative adverse outcomes: A systematic review. Br. J. Anaesth. 2018, 121, 706-721. [CrossRef] [PubMed]

20. Rosner, M.H.; Perazella, M.A. Acute Kidney Injury in Patients with Cancer. N. Engl. J. Med. 2017, 376, 1770-1781. [CrossRef] [PubMed]

21. Jang, W.Y.; Jung, J.K.; Lee, D.K.; Han, S.B. Intraoperative hypotension is a risk factor for postoperative acute kidney injury after femoral neck fracture surgery: A retrospective study. BMC Musculoskelet. Disord. 2019, 20, 131. [CrossRef] [PubMed]

22. Schonberger, R.B.; Nwozuzu, A.; Zafar, J.; Chen, E.; Kigwana, S.; Monteiro, M.M.; Charchaflieh, J.; Sophanphattana, S.; Dai, F.; Burg, M.M. Elevated preoperative blood pressures in adult surgical patients are highly predictive of elevated home blood pressures. J. Am. Soc. Hypertens. 2018, 12, 303-310. [CrossRef] [PubMed]

23. Mathis, M.R.; Naik, B.I.; Freundlich, R.E.; Shanks, A.M.; Heung, M.; Kim, M.; Burns, M.L.; Colquhoun, D.A.; Rangrass, G.; Janda, A.; et al. Preoperative Risk and the Association between Hypotension and Postoperative Acute Kidney Injury. Anesthesiology 2020, 132, 461-475. [CrossRef] [PubMed] 